Journal of Case Reports 2019;9(1):63-66

\title{
PEComa of the Lung: A Rare Entity
}

\author{
Vadim G. Pischik ${ }^{1,2}$, Eugeniy I. Zinchenko ${ }^{1,2}$, Olga S. Maslak ${ }^{2}$, Sergey L. Vorobyev ${ }^{3}$ \\ ${ }^{1}$ Clinical Hospital 122, Saint Petersburg, Russia; ${ }^{2}$ Saint Petersburg State University, Faculty of Medicine, Saint Petersburg, Russia; \\ ${ }^{3}$ National Center of Clinical and Morphological Diagnosis, Saint Petersburg, Russia.
}

\section{Corresponding Author:}

Olga S. Maslak

Email: olga.maslak@me.com

This is an Open Access article distributed under the terms of the Creative Commons Attribution License (creativecommons.org/ licenses/by/3.0).

Received Accepted Published

December 12, 2018

March 17, 2019

March 25, 2019

\begin{abstract}
Background: Perivascular epithelioid cell tumor (PEComa) is extremely rare neoplasm, especially for the pulmonary localization. Clear-cell tumor of the lung, arising from perivascular epithelioid cells, has mainly asymptomatic and benign course. The diagnosis is confirmed on the immunohistochemical examination. The tumors are usually benign, but there are some sarcoma-like masses. Treatment of choice is a surgical resection. Case Report: We report a case of benign PEComa in a 64-year old non-smoking female, accidentally found on a chest X-Ray. VATS anatomic segmentectomy of basal segments was performed. The immunohistochemical examination showed typical features of PEComa. Conclusion: PEComa should be considered in the differential diagnosis of pulmonary nodules. Surgical resection is a treatment of choice followed by immunostaining.
\end{abstract}

Keywords: Fluorescence, Perivascular Epithelioid Cell Neoplasms, Solitary Pulmonary Nodule, Thoracic Surgery.

\section{Introduction}

PEComa is a rare tumor of the lung with less than 50 cases reported worldwide. This is a mesenchymal tumor that consists of immunohistochemically distinctive perivascular epithelioid cells [1]. We report a case of asymptomatic PEComa of the right lower lobe and review of the literature.

\section{Case Report}

A 64 years old non-smoker female was administered to our hospital due to a right pulmonary nodule, accidentally found on a chest X-ray during a routine examination. Her medical history was unremarkable. Chest CT revealed a $19 \mathrm{~mm}$ solitary nodule with well-defined margins in S10 of the right lower lobe [Fig.1a,b]. Abdominal and pelvic CT showed no signs of metastasis. Therefore, video assisted thoracic surgery (VATS) resection of S10 with an express histological examination of the specimen was suggested. A wedge resection of the lesion was performed. The mass had no visible capsule or signs of pleural invasion; central necrosis and fish-meat like appearance were seen on the cut surface. A frozen section did not exclude malignant lesion. Due to close resection margin and not clear morphologic type of the tumor, the VATS anatomic segmentectomy of basal segments and standard mediastinal lymph node dissection were performed. During operation ICG-fluorescence was used for identification of the inter-segmental plane [Fig.2a,b]. The operation time was $110 \mathrm{~min}$ with $15 \mathrm{ml}$ blood loss. Post-operative period was uneventful. The chest drain was removed on a post-operative day two, and patient was discharged without complications.

Histological examination showed structures of the tumor $1.9 \mathrm{~cm}$ in diameter, with microcystic transformation, wide myoepithelial septa, clear cell lining, well-defined margins, and perifocal inflammatory component [Fig.3]. 
Immunohistochemical analysis showed that the tumor had a positive reaction to SMA [Fig.4], CK7, p63 but no reactivity to S100, Melan A, TTF1, RCC, Pax8, Ki67 - 3-5\%. Based on these findings, diagnosis of PEComa of the lung was confirmed. There was no evidence of $\mathrm{R} 1$ resection or lymph nodes involvement. Adjuvant treatment was not administered, and a regular CT follow-up was recommended [Fig.5a,b].

\section{Discussion}

PEComa is a group of rare mesenchymal neoplasms, including angiomyolipoma, lymphangioleiomyomatosis, clear-cell (sugar) tumor of the lung (CCTL), clear-cell myomelanocytic tumor of falciform ligament, and clear-cell tumor of other anatomical sites. WHO defines PEComa as a mesenchymal tumor composed of histologically and immunohistochemically distinctive perivascular epithelioid cells [1]. PEComas have unpredictable pathologic behavior, with mostly benign course. These tumors are mostly seen in a gastrointestinal tract and pelvis, with less than 50 pulmonary cases reported in English literature [2]. CCTL was originally described in 1971 by Liebow and Castleman [3]. It is also called "sugar" tumor because of high glycogen concentration in the cytoplasm [4].

CCTL shows no gender predominance and usually occurs in adults in 40-60s [5], however, two reports describe the tumor in a pediatric population $[6,7]$. But in the paper by J.L. Hornick and C.D. Fletcher PEComas were reported to show a marked female predominance [8]. CCST has been reported in association with LAM, tuberous sclerosis and PEComas of other localization, however, the majority of cases are sporadic $[9,10]$. Only 7 cases of malignant CCST are reported in the worldwide literature [11]. The factors of malignant potential are large size $(>5 \mathrm{~cm})$, infiltrative growth, high nuclear grade and hyper-cellularity, mitoses $>1$ per $50 \mathrm{hpf}$, necrosis or vascular invasion [12]. A local recurrence and metastasis to lung, mediastinum,
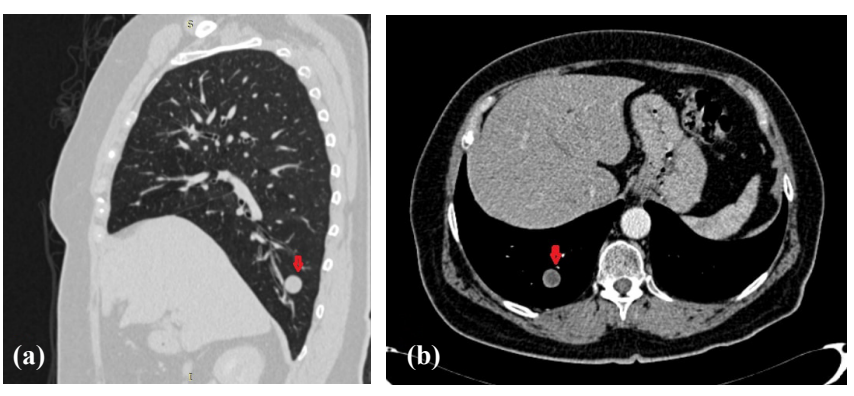

Fig.1(a): A sagittal plane of CT scan in lung window and (b): axial plane in mediastinal window showing $19 \mathrm{~mm}$ solitary nodule with well-defined margins in S10 of the right lower lobe.
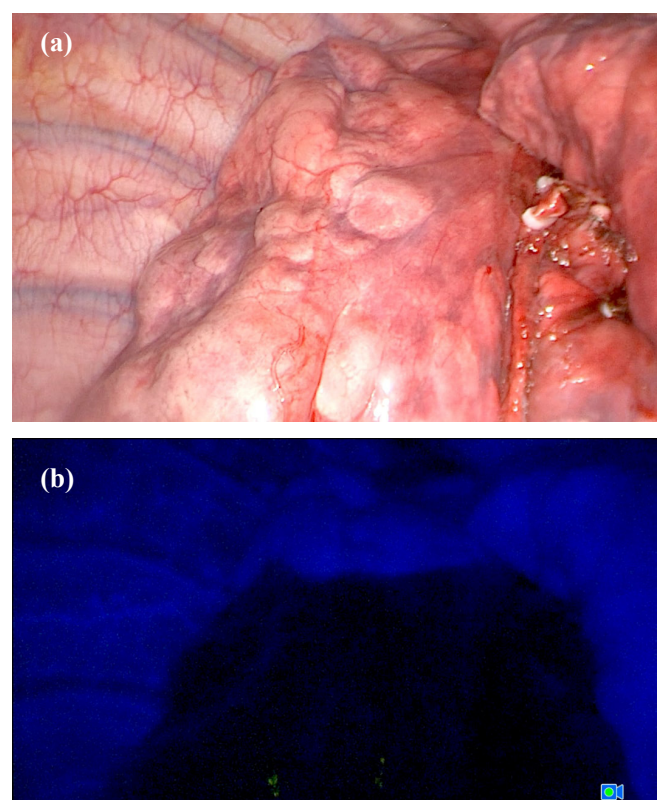

Fig.2(a): An intraoperative image in white light and (b): near-infrared mode used to define intersegmental boundaries for right segmentectomy S7-10.

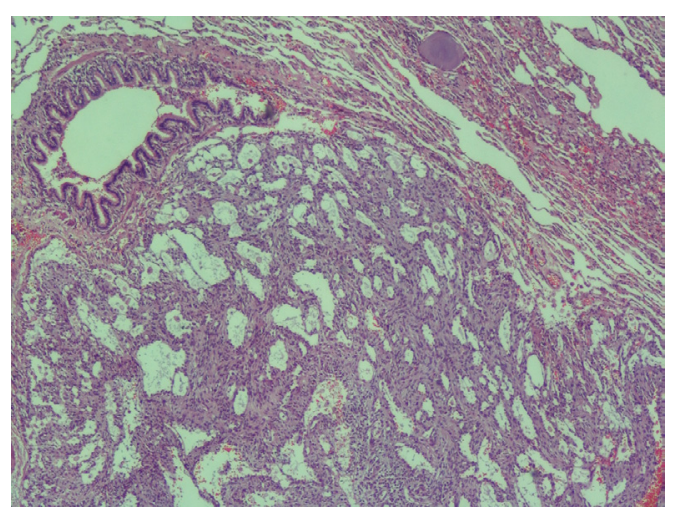

Fig.3: Histological examination of the specimen, showing margins of the tumor. 
adrenal gland, temporal lobe and bones are described in case reports [11].

CCTL usually presents as asymptomatic peripheral solitary nodule with no evidence of cavitation or calcification [13]. The typical characteristics of the CCTL on contrastenhanced CT scans are the intense heterogeneous enhancement in the arterial phase and washout in the delay phase [14]. A single report describes an extensive FDG uptake of the benign tumor [5]. Only two cases presented with hemoptysis $[15,16]$ and one with shortness of breath [17]. Unspecific symptoms are also reported like fever, sputum, fatigue, night sweat, emaciation [4]. S.Sen et al. presented a case of PEComa-associated thrombocytosis that decreased after resection of the tumor [2].

Only in one report, a diagnosis was achieved through transbronchial lung biopsy [18]. Transthoracic biopsy under CT navigation is reported to be helpful in differential diagnosis [12, 19], nevertheless, it was not widely advised due to tumor's rich blood flow and features of sinusoidal vessels [2]. An intra-operative fine needle aspiration is a diagnostic option, however, only single reports demonstrate the effectiveness of this method [1]. Thus, the diagnosis is often made only after immunohistochemical analysis of the specimen that shows a positive reaction to HMB-45, SMA and S-100 and no cytokeratin activity [20].

CCTL is often misdiagnosed as metastatic clear cell renal carcinoma, especially during intra-operative cytological examination [4]. A differential diagnosis should be made between primary pulmonary carcinoma, pulmonary metastasis, including metastatic renal cell carcinoma and metastatic melanoma, solitary fibrous tumor, paraganglioma, tuberculoma, granular cell tumors, oncocytoma, acinic cell tumor, sclerosing hemangioma, hemangiopericytoma, and chemodectoma $[4,5,21]$.

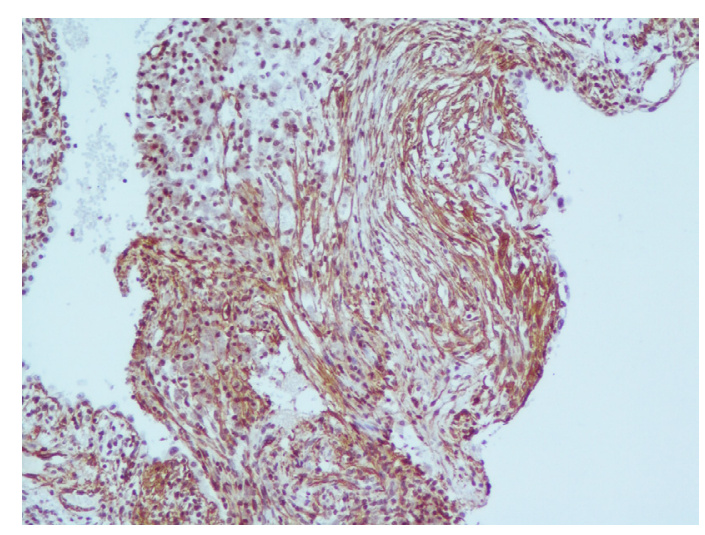

Fig.4: Immunohistochemical analysis of the tumor, showing positive reaction to $S M A$.
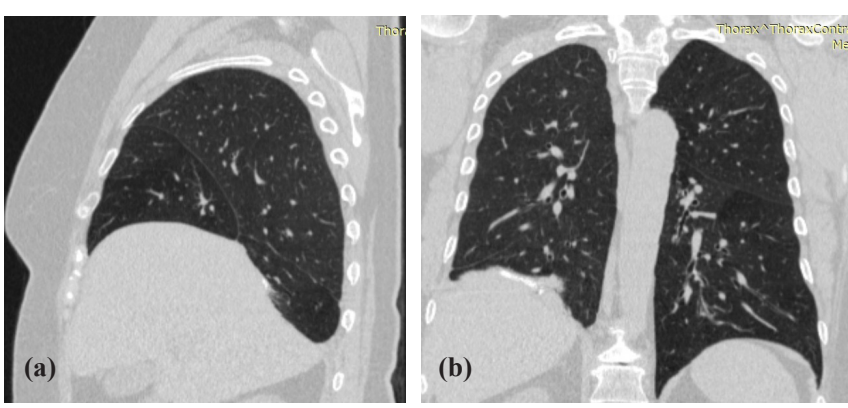

Fig.5: A follow-up chest CT scan in (a): sagittal and (b): coronal planes with no signs of local recurrence.

According to WHO recommendations, lung resection is a treatment of choice and no adjuvant therapy is recommended. A volume of resection is still a matter of debate, including lobectomy, segmentectomy, wedge resection, enucleation, and even pneumonectomy. Recent limited studies reported positive results of targeted therapy administration of mTOR inhibitors in a metastatic PEC tumor of retroperitoneum, kidney, and uterus [11].

\section{Conclusion}

This paper highlights the clinico-pathological aspects of pulmonary PEComa with an overview of possible methods of morphologic verification and discussion of lung resection volume. This disease should be considered in a differential diagnosis of solitary pulmonary nodules. 
Contributors: VGP: manuscript editing, critical inputs into the manuscript, patient management; EIZ: manuscript writing, patient management; OSM: manuscript writing; SLV: morphological examination of the specimen, microphotographs, and critical inputs into the manuscript. OSM will as guarantor. All authors approved the final version of this manuscript.

Funding: None; Competing interests: None stated.

\section{References}

1. Tsilimigras DI, Bakopoulos A, Ntanasis-Stathopoulos I, Gavriatopoulou M, Moris D, Karaolanis G, et al. Clear cell "sugar" tumor of the lung: Diagnostic features of a rare pulmonary tumor. Respir Med Case Rep. 2017;23:52-54.

2. Sen S, Senturk E, Kuman NK, Pabuscu E, Kacar F. PEComa (Clear Cell "Sugar" Tumor) of the lung: a benign tumor that presented with thrombocytosis. Ann Thorac Surg. 2009;88:2013-2015.

3. Liebow AA, Castleman B. Benign clear cell ('sugar') tumors of the lung. Yale J Biol Med. 1971;43:213-222.

4. Chen YB, Guo LC, Huang JA, Ji C, Ling CH. Clear cell tumor of the lung: a retrospective analysis. Am J Med Sci. 2014;347:50-53.

5. Zarbis N, Barth TF, Blumstein NM, Schelzig H. PEComa of the lung: a benign tumor with extensive FDG uptake. Inter Cardiovasc Thorac Surg. 2007;6:676-678.

6. Fukuda T, Machinami R, Joshita $T$, Nagashima $K$. Benign clear cell tumor of the lung in an 8-year-old girl. Arch Pathol Lab Med. 1986;110:664-666.

7. Gora-Gebka M, Liberek A, Bako W, Szumera M, Korzon M, Jaskiewicz K. The "sugar" clear cell tumor of the lung - clinical presentation and diagnostic difficulties of an unusual lung tumor in youth. J Pediatr Surg. 2006;41:2729.

8. Hornick JL, Fletcher CD. PEComa: what do we know so far? Histopathology. 2006;48:75-82.

9. Neri S, Ishii G, Aokage K. Multiple perivascular epithelioid cell tumors: clear cell tumor of the lung accompanied by angiomyolipoma of the liver. Ann Thorac Cardiovasc Surg. 2014;20:453-456.

10. Gunji-Niitsu Y, Kumasaka T, Kitamura S, Hoshika Y, Hayashi T, Tokuda H. Benign clear cell "sugar" tumor of the lung in a patient with Birt-Hogg-Dube syndrome: a case report. BMC Med Genet. 2016;17:85.

11. Lim HJ, Lee HY, Han J, Choi YS, Lee KS. Uncommon of the uncommon: malignant perivascular epithelioid cell tumor of the lung. Korean J Radiol. 2013;14:692696.

12. Wang GX, Zhang D, Diao XW, Wen L. Clear cell tumor of the lung: a case report and literature review. World J Surg Oncol. 2013;11:247.

13. Yeon EK, Kim JI, Won KY. Growth pattern change of a benign clear cell "sugar" tumor of the lung: serial imaging surveillance over seven years. Oncol Let. 2018;15:8652-8654.

14. Kosjerina Z, Kuhajda I, Koledin M, Koledin B, Stojanovic M, Pocuca M. Clear cell "sugar" tumor of the lung - case report. Cent Eur J Med. 2013;8:41-44.

15. Santana AN, Nunes FS, Ho N, Takagaki TY. A rare cause of hemoptysis: benign sugar (clear) cell tumor of the lung. Eur J Cardiothorac Surg. 2004;25:652-654.

16. KavunkalAM, Pandiyan MS, Philip MA, Parimelazhagan KN, Manipadam MT, Cherian VK. Large clear cell tumor of the lung mimicking malignant behavior. Ann Thorac Surg. 2007;83:310-312.

17. Policarpio-Nicolas ML, Covell J, Bregman S, Atkins $\mathrm{K}$. Fine needle aspiration cytology of benign clear cell ("sugar") tumor of the lung: report of a case. Diagn Cytopathol. 2005;36:91-93.

18. Takanami I, Kodaira S, Imamura T. The use of transbronchial lung biopsy to establish a diagnosis of benign clear cell tumor of the lung: report of a case. Surg Today. 1998;28:985-987.

19. Edelweiss M, Gupta N, Resetkova E. Preoperative diagnosis of clear cell "sugar" tumor of the lung by computed tomography-guided fine-needle biopsy and core-needle biopsy. Ann Diagn Pathol. 2007;11:421426.

20. Han B, Jiang G, Wang H, He W, Liu M, Song N. Benign clear cell tumor of the lung. Ann Thorac Surg. 2010;89:2012-2014.

21. Xu Q, Lu C, Li L, Xu K. Clear cell tumor of the lung: two case reports and a review of the literature. Medicine (Baltimore). 2016;95:e4492 (Epub ahead of print). 